\title{
Bacteriological profile of surgical site infections in a tertiary care hospital of western Nepal
}

\author{
Dharm Raj Bhatta $^{1 *}$ (iD, Abhijit Adhikari², Jampa Lhamo Gurung ${ }^{2}$, Niroj Man Amatya², \\ Niranjan Nayak ${ }^{1}$, Shishir Gokhale ${ }^{1}$ \\ 'Department of Microbiology, Manipal College of Medical Sciences, Pokhara, Nepal. Department of Microbiology, \\ Nobel College, Kathmandu, Nepal
}

\begin{abstract}
Introduction: Surgical site infections are one of the most commonly reported nosocomial infections resulting into significant morbidity and mortality. Hospital admission and surgical procedures increase the risk of infection with multidrug resistant pathogens. This study was aimed to determine the bacterial agents associated with surgical site infections and antibiotic resistance patterns of the isolates. Methods: A total of 161 specimens from patients with surgical site infections were included in this study. Isolation, identification and antibiotic susceptibility testing of the isolates was performed by standard microbiological techniques. Results: Out of 161 samples, 94 bacterial isolates were recovered. Gram positive bacteria were isolated in 57.4\% (54/94) cases and Staphylococcus aureus was the most common organism (49/54) with 65.3\% (32/49) methicillin resistant Staphylococcus aureus isolates. All S. aureus isolates were susceptible to vancomycin. Gram negative bacteria constituted 42.6\% (40/94) of total isolates and Escherichia coli was the commonest organism (13/40). Majority of Gram negative isolates were susceptible to amikacin, imipenem and piperacillin-tazobactam. Resistance to imipenem was detected among isolates of E coli, Pseudomonas and Acinetobacter species. Conclusion: Gram positive isolates were more commonly associated with surgical site infections. High percentage of MRSA was detected among the $S$. aureus isolates but no vancomycin resistant $S$. aureus. High percentage of Gram negative isolates was susceptible to imipenem, piperacillin-tazobactam, amikacin and gentamicin.
\end{abstract}

Keywords: Antibiotic resistance, Escherichia coli, nosocomial infections, Staphylococcus aureus, surgical site infections

\section{*Correspondence:}

Dr Dharm Raj Bhatta, PhD

Associate Professor, Department of Microbiology Manipal College of Medical Sciences, Pokhara, Nepal

Email: ddharma2039@gmail.com

Submitted: October 4, 2020

Accepted: May 7, 2021

To Cite: Bhatta DR, Adhikari A, Gurung JL, Amatya NM, Nayak N, Gokhle S. Bacteriological profile of surgical site infections in a tertiary care hospital of western Nepal. JGMC Nepal. 2021;14(1):33-8.

DOI: $10.3126 /$ jgmcn.v14i1.32703

\section{INTRODUCTION}

Human skin as a part of innate immune system provides effective barrier against microbial invasion into the underlying tissues. In addition, commensal microbial flora of skin reduces colonization by harmful pathogens. Surgical procedures damage the integrity of skin and facilitate colonization and proliferation of microorganisms resulting into surgical site infections (SSIs). Surgical site infections are defined as infections occurring at the surgical wound within 30 days after surgery or within one year if an implant is left in place. ${ }^{1}$

Surgical site infections are one of the major causes of healthcare associated infections resulting into high morbidity and mortality. ${ }^{2,3}$ SSIs are the third most commonly reported nosocomial infection and account for approximately a quarter of all nosocomial infections. The global scenario of SSIs ranges from $2.5 \%$ to $41.9 \%$., National Centre for Health Statistics and National Healthcare Safety Network suggested that 2,50,000 to 1 million patients develop SSIs out of 26.6 million surgical procedures performed annually in USA. ${ }^{6}$ In Nepal, studies have reported prevalence rate of SSIs ranging from 7.3 to $23 \%{ }^{7,8}$ 
Despite technical advances in infection control and surgical practices, even in hospitals with modern facilities, SSIs remain continue to be a major problem. ${ }^{9}$ These infections are caused by exogenous and/or endogenous microorganisms that enter the surgical site either during or after the surgical procedure. Infections usually develop within five to seven days of surgery. The presentation of an infected surgical wound can be characterized by pain, tenderness, warmth, erythema, swelling and pus formation. The factors that influence risk of SSIs include age, nutritional status, pre-existing infection, co-morbid illness, pre-operative site preparation, poor surgical technique, prolonged duration of surgery and inadequate sterilization of surgical instruments. ${ }^{9}$ In addition, the virulence factors of the organisms, physiological state of the wound tissue and immunity of the host are also important factors. ${ }^{10}$

Pathogens that are able to survive in the hospital environment for long period and resist the action of disinfectants are particularly more important for SSIs. These infections are further complicated by increasing prevalence of multidrug resistant organisms like methicillin resistant Staphylococcus aureus (MRSA), vancomycin resistant Enterococci (VRE), multidrug resistant E coli, Pseudomonas spp and Acinetobacter spp. ${ }^{11,12}$

Limited data is available regarding etiological agents of SSIs and resistance profile of the isolates in most of the developing countries including Nepal.,8 Therefore, present study was conducted to identify the causative agents of SSIs and antibiotic resistance patterns of the isolates. Findings of the study would be beneficial for medical practitioners to select appropriate empirical antimicrobial therapy and implementation of infection control measures.

\section{METHODS}

Study setting and period: This hospital based cross-sectional study was undertaken at Manipal Teaching Hospital, Pokhara, Nepal, between September 2019 to December 2019. Approval from the Institutional Review Committee (IRC) of Manipal College of Medical Sciences (MCOMS), Pokhara, Nepal, was obtained before the commencement of the study. Manipal Teaching Hospital provides surgical care to the patients visiting various department including General Surgery, Neurosurgery, Urosurgery, Orthopedics, Obstetrics and Gynecology, Otorhinolaryngology, Ophthalmology and Dental departments. This hospital has eight operation theaters and performs approximately 200 different surgeries in a month with seasonal variation.

Specimen collection and transportation: A total of 161 swabs from infected surgical sites were included in this study. All the specimens were immediately transported and processed in the clinical microbiology laboratory. Sociodemographic details, medical history and other demographic data were retrieved from medical record using structured format

Isolation and identification of bacterial isolates: Samples were inoculated on Blood agar, Chocolate agar and MacConkey agar plates. Inoculated plates were aerobically incubated at $37^{\circ} \mathrm{C}$ for 24 to 48 hours. Blood agar and chocolate agar plates were incubated under 5\% CO2 in a candle jar. Identification of the isolates was performed by standard microbiological techniques such as colony morphology, Gram stain, IMViC test, catalase test, coagulase test etc. ${ }^{13}$ Plates showing no bacterial growth after 48 hours of incubation were discarded and reported accordingly.

Antibiotic susceptibility testing: Antibiotic susceptibility testing of the isolates was performed on Mueller Hinton agar (HI Media, Mumbai, India) by the Kirby-Bauer disc diffusion method. ${ }^{14}$ Bacterial isolates showing resistance to at least one agent in three or more antimicrobial categories were labeled as multi drug resistant (MDR). ${ }^{15}$ Methicillin resistance among $S$. aureus isolates were screened by the cefoxitin $(30 \mu \mathrm{g})$ disc diffusion method. ${ }^{14}$ Extended Spectrum Beta Lactamase (ESBL) production among Gram negative bacilli was detected by standard methods. ${ }^{14}$ Minimal inhibitory concentration (MIC) of vancomycin was performed by the Epsilometer test following CLSI guidelines to rule out the possibility of vancomycin resistant Staphylococcus aureus (VRSA) and vancomycin intermediate Staphylococcus aureus (VISA). ${ }^{14}$

\section{RESULTS}

Specimens from 161 patients with clinical features of post-surgical infection were included in this study of which, 104 (64.6\%) were males and 57 (35.4\%) were females. Bacterial growth was detected in 80/161 (53 male and 27 female) samples yielding a total of 94 bacterial isolates. Single bacterial isolate were recovered from 66 (82.5\%) samples whereas 14 (17.5\%) samples had two types of bacteria. Details of age and gender distribution of the patients are shown in Table 1.

Table 1: Age and gender distribution of the patients

\begin{tabular}{|c|c|c|c|c|c|c|}
\hline \multirow{2}{*}{ Gender } & \multicolumn{5}{|c|}{ Age groups (years) } & \multirow{2}{*}{ Total } \\
\hline & $<20$ & $20-40$ & $41-60$ & $61-80$ & $>80$ & \\
\hline Male & 21 & 20 & 24 & 27 & 05 & 97 \\
\hline Female & 07 & 18 & 17 & 20 & 02 & 64 \\
\hline Total & 28 & 38 & 41 & 47 & 07 & 161 \\
\hline
\end{tabular}


Gram positive bacteria were isolated in 57.4\% (54/94) cases and S. aureus was the most common organism (49/54). Gram negative bacteria constituted 42.6\% (40/94) of total isolates and $E$ coli was the commonest organism (13/40) followed by Pseudomonas species (11/40) and others. Details of the etiological agents and clinical conditions requiring surgery are depicted in Table 2.

Table 2: Frequency of etiological agents associated with surgical sites

\begin{tabular}{lcccccc}
\hline \multirow{1}{*}{ Etiological agents } & \multicolumn{7}{c}{ Indications for surgery } & & \\
& Appendicitis & Hernia & Ovarian Cyst Ulcer & Others & Total \\
MRSA & 10 & 03 & 01 & 07 & 11 & 32 \\
MSSA & 06 & 01 & & 04 & 06 & 17 \\
Pseudomonas spp. & 01 & 01 & - & - & 09 & 11 \\
Acinetobacter spp. & 01 & - & - & - & 06 & 07 \\
E coli & 03 & 01 & 01 & 02 & 06 & 13 \\
Proteus spp. & 01 & - & - & - & 02 & 03 \\
Klebsiella pneumoniae & 01 & - & - & - & 04 & 05 \\
Enterobacter spp. & 01 & - & - & - & - & 01 \\
Enterococcus spp. & - & - & 01 & - & 03 & 04 \\
Streptococcus pyogenes & - & - & - & - & 01 & 01 \\
Total & 24 & 06 & 03 & 13 & 48 & 94 \\
\hline
\end{tabular}

Out of 49 S. aureus isolates, 32 (65.3\%) were MRSA and remaining were MSSA. Majority of $S$. aureus isolates were susceptible to amikacin and tetracycline. All isolates of $S$. aureus and Enterococcus species were susceptible to vancomycin. Vancomycin E test for MRSA (Figure: 1) showed all isolates were susceptible with MIC values ranging from $0.75 \mu \mathrm{g} / \mathrm{ml}$ to $1 \mu \mathrm{g} / \mathrm{ml}$. Among MRSA isolates, $81.2 \%$ (26/32) were multidrug resistant (MDR). Details of antibiotic resistance patterns of Gram positive isolates are shown in Table 3.

Table 3: Antibiotic resistance patterns of Gram positive isolates

\begin{tabular}{lccc}
\hline \multicolumn{1}{c}{ Antibiotic } & $\begin{array}{c}\text { S. aureus } \\
(\mathbf{N = 4 9 )} \\
\text { Frequency (\%) }\end{array}$ & $\begin{array}{c}\text { Enterococcus } \\
\text { species } \\
\text { (N= 04) } \\
\text { Frequency (\%) }\end{array}$ & $\begin{array}{c}\text { Streptococcus } \\
\text { pyogenes } \\
\text { (N= 01) } \\
\text { Frequency (\%) }\end{array}$ \\
Amikacin & $04(8.1 \%)$ & -- & -- \\
Gentamicin & $15(30.6 \%)$ & -- & 00 \\
Tetracycline & $04(8.1 \%)$ & $01(25 \%)$ & -- \\
Teicoplanin & -- & 00 & -- \\
Chloramphenicol & -- & 00 & -- \\
Co-Trimoxazole & $08(16.2 \%)$ & -- & 00 \\
Erythromycin & $34(69.3 \%)$ & $04(100 \%)$ & $01(100 \%)$ \\
Clindamycin & $29(59.1 \%)$ & -- & -- \\
Cefoxitin & $32(65.3 \%)$ & -- & -- \\
Ciprofloxacin & $33(67.3 \%)$ & $04(100 \%)$ & $01(100 \%)$ \\
Vancomycin & 00 & 00 & -- \\
\hline
\end{tabular}

Majority of Gram negative isolates were susceptible to amikacin, imipenem and piperacillin-tazobactum. Out of
13 E coli isolates, $46.2 \%$ were ESBL producers. Klebsiella species showed higher resistance to amikacin, gentamicin, ciprofloxacin and piperacillin-tazobactum as compared to $E$ coli isolates. However, the difference was statistically insignificant. Among Klebsiella species, 40\% (2/5) isolates were ESBL producers. Majority of the Pseudomonas species were susceptible to the commonly used antibiotics except ceftazidime. Among non fermentative Gram negative bacilli, higher resistance was observed among Acinetobacter species as compared to Pseudomonas species. Resistance to imipenem was detected in one isolate of $E$ coli, one isolate of Pseudomonas species and two isolates of Acinetobacter species. Details of antibiotic resistance patterns of Gram negative isolates are shown in Table 4.

Table 4: Antibiotic resistance patterns of Gram negative isolates

\begin{tabular}{|c|c|c|c|c|c|}
\hline Antibiotic & $\begin{array}{c}E \text { coli } \\
(\mathrm{N}=13) \\
\text { Frequency }(\%)\end{array}$ & $\begin{array}{c}\text { Klebsiella } \\
\text { species } \\
(\mathrm{N}=05) \\
\text { Frequency }(\%)\end{array}$ & $\begin{array}{c}\text { Pseudomonas } \\
\text { species } \\
(\mathrm{N}=11) \\
\text { Frequency }(\%)\end{array}$ & $\begin{array}{c}\text { Acinetobacter } \\
\text { species } \\
(\mathrm{N}=07) \\
\text { Frequency }(\%)\end{array}$ & 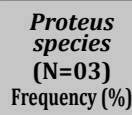 \\
\hline Amikacin & $01(7.7 \%)$ & $01(20 \%)$ & $01(9 \%)$ & $04(57.1 \%)$ & 00 \\
\hline Gentamicin & $02(15.4 \%)$ & $01(20 \%)$ & $01(9 \%)$ & $03(42.8 \%)$ & $01(33.3 \%)$ \\
\hline Ciprofloxacin & $05(38.5 \%)$ & $02(40 \%)$ & $02(18.1 \%)$ & $04(57.1 \%)$ & 01 (33.3\%) \\
\hline Imipenem & $01(7.7 \%)$ & -- & $01(9 \%)$ & $02(28.5 \%)$ & 00 \\
\hline Cefepime & $06(46.2 \%)$ & 02 (40\%) & 02 (18.1\%) & $04(57.1 \%)$ & 01 (33.3\%) \\
\hline $\begin{array}{l}\text { Piperacillin- } \\
\text { Tazobactam }\end{array}$ & $02(15.4 \%)$ & $01(20 \%)$ & $01(10 \%)$ & $02(28.5 \%)$ & $01(33.3 \%)$ \\
\hline Cefotaxime & $06(46.2 \%)$ & 02 (40\%) & -- & -- & 01 (33.3\%) \\
\hline Ceftazidime & $06(46.2 \%)$ & & 05 (45.4\%) & $04(57.1 \%)$ & -- \\
\hline Tobramycin & & & $1(9 \%)$ & $3(42.8 \%)$ & -- \\
\hline
\end{tabular}

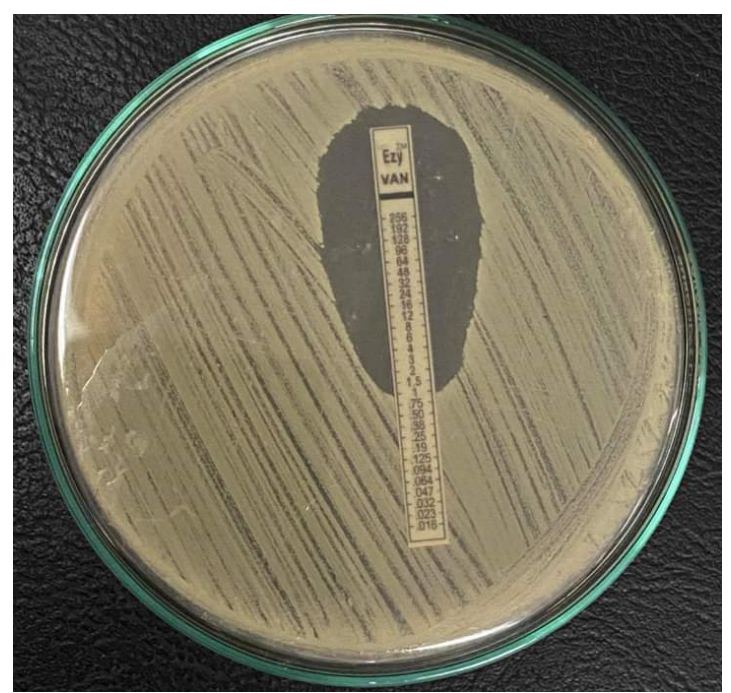

Figure 1: Vancomycin E test of MRSA

\section{DISCUSSION}

Despite advancement in the surgical and antiseptic/disinfection techniques, management of SSIs remains challenging. Hospital environmental surfaces, objects, instruments and healthcare professionals serve as a potential reservoir 
for infectious agents. ${ }^{16}$ Bacterial agents survive on these areas for variable duration of time depending upon number of factors. Increasing resistance among the nosocomial bacterial pathogens and emergence of multidrug resistant isolates further contributes to the increasing incidences of SSIs. In addition, patient's own bacterial flora get opportunity to colonize and multiply in the subcutaneous tissues resulting into post-operative wound infections. SSIs are reported as third most common nosocomial infections following urinary tract infections and pneumonias. ${ }^{17}$

The prevalence of SSIs, etiological agents and antimicrobial resistance patterns of the isolates vary from hospital to hospital, geographical area and country depending upon various factors. These factors include diversity of the study population, antimicrobial use patterns, microbial carrier rates and infection control practices. Therefore, it is important to have adequate data regarding etiological agents and resistance patterns of the isolates at local, regional and national level for better management of SSIs. S. aureus, is a major human pathogen and a predominant cause of SSIs worldwide with a prevalence rate ranging from $4.6 \%$ to $54.4 \% .^{18}$

In our study, bacterial growth was detected only in only $49.7 \%$ (80/161) samples. Low rate of bacterial isolation could be due to prophylactic use of antibiotics like cefazolin, ceftriaxone and cefaperazone sulbactam. Anaerobic bacteria constitute a significant part of indigenous flora and have been isolated from surgical sites. ${ }^{19}$ Association of anaerobic bacterial pathogens could be another possible reason for low rate of bacterial isolation in our study.

According to CDC, S. aureus, CoNS and E coli were the most prevalent organisms associated with SSIs. ${ }^{20}$ In our study, two most common bacterial isolates were $S$. aureus and $E$ coli. S. aureus, being normal flora of skin, nasal cavity and various other anatomical sites, likely to colonize the surgical site resulting into endogenous infection. In addition $S$. aureus is one of the most prevalent nosocomial pathogens, colonizing healthcare workers and residing on hospital environmental surfaces. ${ }^{16}$ Similar findings have been reported from Nepal and other countries. ${ }^{21-24}$

In our study, methicillin resistance was detected among $65.3 \%$ S. aureus isolates, which is higher than other studies conducted within and outside Nepal. ${ }^{22,23,25}$ High rate of MRSA in our study could be due to prophylactic use of antibiotics and high prevalence of MRSA in the Western region of Nepal. Isolation of high percentage of MRSA from surgical sites limits the therapeutic options and prolongs the duration of hospital stay. However, no vancomycin re- sistant isolate was detected in this study. Research findings from other hospitals of Nepal, have reported the emergence of VISA and VRSA. ${ }^{26}$

Gram negative isolates comprised of 42.6\% (40/94) of all bacterial isolates. Three most common Gram negative isolates were E coli (32.5\%), Pseudomonas species (27.5\%) and Klebsiella spp (12.5\%). Similar findings have been reported by other studies conducted in Nepal and India. ${ }^{22,27}$ Some of the studies have reported Pseudomonas species as most common agent associated with SSIs. ${ }^{27,28}$ The highest prevalence of $E$ coli among Gram negative isolates in our study could be associated with spread of colonizing flora from perineal region. High rate of isolation of Pseudomonas species can be attributed to their being a normal flora of human skin and important contaminants of hospital surfaces, surgical instruments and even some of the chemical disinfectants. High percentage of ESBL producing Gram negative isolates indicate increasing drug resistance and decreased susceptibility to third generation cephalosporins. Increased resistance among Gram negative isolates is probably due to prophylactic use of antibiotics like cefazolin, ceftriaxone and cefaperazone sulbactam. Emergence of imipenem resistant Gram negative isolates is global threat with very limited or no therapeutic options. Imipenem resistant Gram negative isolates have been reported among patients admitted in Intensive Care Units (ICUs) of Manipal Teaching hospital..$^{29}$ Operation theaters, ICUs and Post-operative ward of our hospital are located adjacent to each other. These isolates probably get transferred from ICU to Post-operative ward by healthcare workers resulting into SSIs.

\section{CONCLUSIONS}

Association of Gram positive bacteria in SSIs was found higher as compared to Gram negative isolates. S. aureus was the most common Gram positive bacterial isolate and $E$ coli was the most frequently isolated Gram negative bacteria. High percentage of MRSA was detected among the $S$. aureus isolates without any VISA and VRSA. High percentage of Gram negative isolates was susceptible to imipenem, piperacillin-tazobactam, amikacin and gentamicin except Acinetobacter species. Resistance to imipenem was detected among isolates of $E$ coli, Pseudomonas species and Acinetobacter species. Periodic monitoring of bacteriological agents causing SSIs and antibiotic resistance patterns is necessary to understand the changing trends of resistance pattern. In this view, findings of this study are important for successful management of SSIs and selecting antimicrobial agents for prophylactic use. 


\section{LIMITATIONS}

Anaerobic bacterial culture was not performed due to unavailability of the resources. Fungal culture was not performed.

\section{ACKNOWLEDGEMENTS}

The authors are thankful to all the staffs of Microbiology and Surgery Department, Manipal Teaching Hospital, Pokhara, Nepal, for their help and support. We are grateful to nursing staffs of Post-operative ward for their help.

Conflict of Inter : The authors declare that they have no conflict of interest.

FUNDING: No external funding for this study.

\section{REFERENCES}

1. Townsend CM, Beauchamp RD, Evers BM, Mattox KL. Sabiston Textbook of Surgery: The Biological Basis of Modern Surgical Practice, $18^{\text {th }}$ ed. Philadelphia: Saunders; 2012. p. 299-327.

2. Amare B, Abdurrahman Z, Moges B, Ali J. Postoperative surgical site bacterial infections and drug susceptibility patterns at Gondar University Teaching Hospital, Northwest Ethiopia. Journal of Bacteriology \& Parasitology. 2011;2(8):126. DOI: 10.4172/2155-9597.1000126

3. Le TA, Sohn AH, Nguyen PT, Vo TC, Vo VN, Tran Nguyen TH, et al. Microbiology of surgical site infections and associated antimicrobial use among Vietnamese orthopedic and neurosurgical patients. Infect Control Hosp Epidemiol. 2006;27(8):855-62. DOI: 10.1086/506400

4. Brown S, Kurtsikahvi G, Alonso EJ, Ghadua M, Ahmeteli L, Bochoidze T, et al. Prevalence and predictors of SSI in Tbilisi Republic of Georgia. J Hosp Infect. 2007;66(2):160-6. DOI: 10.1016/j.jhin.2007.03.007

5. Mawalla B, Mshana SE, Chalya PL, Imirzalioglu C, Mahalu W. Predictors of surgical site infections among patients undergoing major surgery at Bugando Medical Centre in Northwestern Tanzania. BMC Surgery. 2011;11-21. DOI:10.1186/1471-2482-11-21

6. National Nosocomial infections surveillence (NNIS) system report, data summary from January 1992 through June 2004. Am J Infect control 2004;32(8):470-85. DOI: 10.1016/ S0196655304005425

7. Giri S, Kandel BP, Pant S, Lakhey PJ, Singh YP, Vaidya P. Risk factors for surgical site infections in abdominal surgery: a study in Nepal. Surg Infect (Larchmt). 2013;14(3):313-8. DOI: $10.1089 /$ sur.2012.108

8. Giri BR, Pant HP, Shankar PR, Sreeramareddy CT, Sen PK.
Surgical site infection and antibiotics use pattern in a tertiary care hospital in Nepal. J Pak Med Assoc. 2008;58(3):148-51. PMID: 18517124.

9. Owens CD, Stoessel K. Surgical site infections: epidemiology, microbiology and prevention. J Hosp Infect. 2008;70(2):310. DOI: 10.1016/S0195-6701(08)60017-1

10. Masaadeh HA, Jaran AS. Incident of Pseudomonas aeruginosa in post-operative wound infection. Am J Infect Dis. 2009;5(1):1-6. DOI: 10.3844/ajidsp.2009.1.6.

11. Adegoke A, Mvuyo T, Okoh AI, Steve J. Studies on multiple antibiotic resistant bacterial isolated from surgical site infection. Scientific Research and Essays. 2010;5(24):387681.

12. Mulu W, Kibru G, Beyene G, Damtie M. Postoperative nosocomial infections and antimicrobial resistance pattern of bacteria isolates among patients admitted at Felege Hiwot Referral Hospital, Bahirdar, Ethiopia”. Ethiopian Journal of Health Sciences. 2012;22(1):7-18. PMID: 22984327.

13. Cheesbrough M. District laboratory practice in tropical countries. 2nd ed. New York, USA: Cambridge University Press; 2006. p. 62-70.

14. Pa W. Clinical and Laboratory Standards Institute, Performance standards for antimicrobial susceptibility testing, twenty-second informational supplement, CLSI, Document, USA 2017:M100-S27.

15. Magiorakos AP, Srinivasan A, Carey RB, Carmeli Y, Falagas $\mathrm{ME}$, Giske CG, et al. Multidrug-resistant, extensively drugresistant and pandrug-resistant bacteria: an international expert proposal for interim standard definitions for acquired resistance. Clin Microbiol Infect. 2012;18(3):26881. DOI: 10.1111/j.1469-0691.2011.03570.x.

16. Bhatta DR, Hamal D, Shrestha R, Subramanya SH, Baral N, Singh RK, et al. Bacterial contamination of frequently touched objects in tertiary care hospital of Pokhara, Nepal: how safe are our hands? Antimicrobial Resistance and Infection Control. 2018;7:97. DOI: org/10.1186/s13756018-0385-2.

17. Lilani SP, Jangale N, Chaudhary A, Daver GB. Surgical site infection in clean and clean-contaminated cases. Ind J Med Microbiol. 2005;23(4):249-52. PMID: 16327121.

18. Chakarborty SP, Mahapatra SK, Bal M, Roy S. Isolation and identification of vancomycin resistant Staphylococcus aureus from post-operative pus sample. Al Ameen J Med Sci. 2011;4(2):152-68.

19. Ananth-Shenoy P, Vishwanath S, Targain R, Shetty S, SunilRodrigues G, Mukhopadhyay C, et al. Anaerobic infections in surgical wards: a two year study. Iran J Microbiol. 2016;8(3):181-6. PMID: 27928485. 
20. National Nosocomial Infections Surveillance (NNIS) System, "National Nosocomial Infections Surveillance (NNIS) report, data summary from October 1986-April 1996. American Journal of Infection Control.1996;24(5):380-8. PMID: 8902113.

21. Chaudhary R, Thapa SK, Rana JC, Shah PK. Surgical Site Infections and Antimicrobial Resistance Pattern. J Nepal Health Res Council. 2017;15(36):120-3. DOI: org/10.33314/ jnhrc.v15i2.1048

22. Raza MS, Chander A, Ranabhat A. Antimicrobial Susceptibility Patterns of the Bacterial Isolates in Post-Operative Wound Infections in a Tertiary Care Hospital, Kathmandu, Nepal. Open Journal of Medical Microbiology. 2013;3:159-63. DOI: 10.4236/ojmm.2013.33024

23. Negi V, Pal S, Juyal D, Sharma MK, Sharma N. Bacteriological Profile of Surgical Site Infections and Their Antibiogram: A Study From Resource Constrained Rural Setting of Uttarakhand State, India. Journal of Clinical and Diagnostic Research. 2015;9(10):17-20. DOI: 10.7860/ JCDR/2015/15342.6698

24. Nur-e-elahi M, Jahan I, Siddiqui O, Ahmed S, Joarder A, Faruque $S$, et al. Wound infection in surgery department in BSMMU: A study of 100 cases. Journal of the Bangladesh Society of Anesthesiologists. 2014;24(2):65-9. DOI: org/10.3329/jbsa.v24i2.19804

25. Dessie W, Mulugeta G, Fentaw S, Mihret A, Hassen M, Abebe E. Pattern of Bacterial Pathogens and Their Susceptibility Isolated from Surgical Site Infections at Selected Referral Hospitals, Addis Ababa, Ethiopia. International Journal of Microbiology. 2016;1-8. DOI: org/10.1155/2016/2418902

26. Lama U, Shah D, Shrestha UT. Vancomycin Resistant Staphylococcus aureus Reported from Tertiary Care Hospital in Nepal. TUJM. 2017;4(1):63-72. DOI: org/10.3126/tujm. v4i0.21679

27. Ranjan KP, Ranjan N, Bansal SK, Arora DR. Prevalence of Pseudomonas aeruginosa in Post-operative Wound Infection in a Referral Hospital in Haryana. India. J Lab Physicians. 2010;2(2):74-7. DOI: 10.4103/0974-2727.72153

28. Kokate SB, Rahangdale V, Katkar VJ. Study of Bacteriological Profile of Post Operative Wound Infections in Surgical Wards in a Tertiary Care Hospital. International Journal of Contemporary Medical Research. 2017;4(1):232-35.

29. Bhatta DR, Hamal D, Shrestha R, HS Supram, Joshi P, Nayak N, et al. Burden of multidrug resistant respiratory pathogens in intensive care units of tertiary care hospital. Asian Journal of Medical Sciences. 2019;10(2):14-9. DOI: org/10.3126/ajms. v10i2.21098 